\title{
Electrochemical and viscoelastic evolution of dodecyl sulfate-doped polypyrrole
}

\section{films during electrochemical cycling}

Wanli Gao, Ozlem Sel*, Hubert Perrot*

Sorbonne Universités, UPMC Univ. Paris 06, CNRS, UMR 8235, LISE, F-75005, Paris, France.

\section{ABSTRACT:}

The correlation between electrochemical and viscoelastic properties of electrodeposited dodecylsulfate-doped polypyrrole (PPy-DS) during electrochemical cycling process was described through combining electrochemical quartz-crystal microbalance (EQCM), $a c$-electrogravimetric characterizations and electroacoustic measurements. As the PPy-DS electrode evolves during the course of consecutive cycling in aqueous $\mathrm{NaCl}$ electrolyte, the film exhibits $(i)$ an obvious ion-selective transition from cations to anions in the charge compensation process; (ii) an inferior electrochemical performance accompanied with increased stiffness (increased storage moduli, $\mathrm{G}^{\prime}$ ); and (iii) depleted capability of ionic exchange through film/electrolyte interface. PPy-DS conducting polymer electrodes (CPEs) are of interest in energy storage and the relationship between electrochemical and viscoelastic properties during electrochemical cycling process is essential for promoting the performance of these devices. In this perspective, $a c$-electrogravimetry combined with electroacoustic measurements can be suggested as an alternative method to synchronously probe the electrochemical and mechanical evolution and has the potential to offer a generalized route to study aging mechanism of CPEs.

KEYWORDS: Polypyrrole, electrochemical quartz-crystal microbalance (EQCM), $a c$-electrogravimetry, ionic flux, electroacoustic measurements.

E-mail address: ozlem.sel@upmc.fr (O. Sel).

E-mail address: hubert.perrot@upmc.fr (H. Perrot). 


\section{Introduction}

Species transfer in conducting polymer electrodes (CPEs) plays a key role in numerous applications, such as electrochemical sensors [1, 2], batteries [3, 4] and supercapacitors $[5,6]$. Up to date, significant attention has been drawn to enhance the ionic transfer/transport and cycling stability of CPEs to devise electronics with effective energy storage capability [7-10], thereby demanding a thorough understanding of the ion transfer behavior at the CPEs/electrolyte interface. Another issue is that the CPEs experience inevitable structural changes in practical applications primarily due to the electrochemical aging of the polymer. The latter may aggravate the mechanical properties of CPEs which can be reflected in the viscoelastic variations of polymer electrodes during electrochemical cycling [11-13]. Many CPEs have been studied for their appealing electrochemical properties [14], such as poly(3,4-ethylenedioxythiophene) (PEDOT) [15, 16], polypyrrole (PPy) [17-19], polyaniline (PANI) $[8,20]$ and polythiophene (PHT) [21, 22]. PPy has been exploited in considerable amount of researches, due to its relatively higher pseudocapacitance and lower cost, as well as its particularly supreme flexibility in morphology and structure [23]. However, inferior cycle stability caused by significant dimensional changes during charge-discharge process greatly hinders their applications. Therefore, the relationship between internal structure and film properties has been scrutinized with the purpose of promoting the performance of CPEs in applications (i.e. energy storage).

Electrochemical quartz-crystal microbalance (EQCM) and its coupling with electrochemical impedance spectroscopy (the so-called ac-electrogravimetry) have proved themselves as baseline analytical tools to probe electrochemical processes, with tremendous benefits in in situ capturing ionic fluxes in various electrodes, including 
carbon based electrodes [24-26] and CPEs [27, 28]. Considerable amount of work has focused on the exploration of electrochemical properties of CPEs, which has been regarded as a prerequisite for improving performances of electrochemical devices [29, 30]. However, their physical or viscoelastic properties are of equal importance especially for the electrode cycling stability and should not be neglected. The ionic fluxes accompanied the free solvent molecules transfer during charging-discharging process may bring about the periodic potential-dependent volumetric changes of the electrodes (i.e., swelling and shrinking) [14, 22]. These processes are likely to result in a wide variety of unpredictable mechanical defects, i.e. polymer electrode fatigue, stress concentration and delamination from current collector. Thus, a measurement methodology capable of capturing the ionic transfer as well as viscoelastic evolution of the CPEs synchronously is highly desirable.

The viscoelastic properties of CPEs have been extensively investigated through the electroacoustic impedance method [31-33], by which the storage $(G)$ and loss moduli $\left(G^{\prime \prime}\right)$ of the polymer film can be determined. As the film ages, the viscoelastic changes may occur inside the film due to polymer chain rearrangements and species transfer through film/electrolyte interface [32]. Hillman and co-workers have reported an increase in the stiffness of PANI films due to insertion of anions and the expulsion of the solvent molecules $[12,34]$. Bund et al. observed that the influx of anions may increase the stiffness of PEDOT film and the variations of $G^{\prime}$ and $G^{\prime \prime}$ were correlated with concentrations of charged species within film $[35,36]$. It is considered that such viscoelastic changes are somewhat associated with the electrochemical performance of the film, as the flux of ions and solvent during the charge-discharge process can modify the intermolecular interactions between polymer chains, which in turn substantially 
affect the film viscoelasticity. Herein, a methodology which combines the EQCM, $a c$-electrogravimetry and electroacoustic measurements was proposed to get a broader view of the physico-chemical interactions inside the CPEs over the course of electrochemical aging. The particularity of this methodology stems from the utility of EQCM together with ac-electrogravimetry and electroacoustic impedance for electrogravimetric evaluation and for viscoelastic tests, respectively.

With the aim of synchronous description of the relationship between electrochemical properties and viscoelastic evolution during PPy electrode electrochemical cycling, the combined methodology (involving EQCM, ac-electrogravimetry and electroacoustic impedance measurements) was applied to characterize PPy film doped with $\mathrm{DS}^{-}$anions (PPy-DS) after every 25 charge/discharge cycles in aqueous electrolytes until $175^{\text {th }}$ cycle was reached. Due to the nanometric film thickness, film/electrolyte configuration can be considered as a zoom of a real macroscopic electrochemical system. During the limited number of cycles, various phenomena might be observed which can permit to predict an eventual degradation of CPEs in energy storage devices. This systematic study is expected to provide insights into the relationship between the internal structure of the CPE film and the ability to maintain its electrochemical and mechanical performance. To the best of our knowledge, such systematic study has not yet been reported. In previous works of our group (ref. 11 and 27), either materials and dopants or the methods to explore the mechanical properties were different. The influences of aging degree and applied potential on the species transfer (charged or uncharged), hydration/dehydration of ions and free solvents motion and intimately related viscoelastic changes of PPy-DS electrode were investigated during film aging upon cycling and a model was proposed to illustrate the electrochemical cycling process. 


\section{Experimental}

\subsection{Film preparation and characterization}

Pyrrole solution (Py), sodium dodecyl sulphate $(\mathrm{NaDS})$ and $\mathrm{NaCl}$ salts were purchased from Sigma Aldrich. The Py monomer was distilled before use and kept at $-20{ }^{\circ} \mathrm{C}$. All the solutions were prepared with bi-distilled water.

Polypyrrole films doped with $\mathrm{DS}^{-}$anions were electrodeposited on the gold electrode $\left(0.2 \mathrm{~cm}^{2}\right)$ of a quartz crystal resonator ( $9 \mathrm{MHz}-\mathrm{AWS}$, Valencia, Spain) where a platinum grid and a saturated calomel electrode (SCE) are used as counter and reference electrode, respectively. The PPy-DS films were electrodeposited by cyclic voltammetry ( 2 cycles) from $0.675 \mathrm{~V}$ to $0 \mathrm{~V} v s$. SCE at $10 \mathrm{mV} \cdot \mathrm{s}^{-1}$ in a solution of $0.1 \mathrm{M}$ pyrrole and $0.05 \mathrm{M}$ NaDS $[27,37]$. The average film thickness of the electrogenerated PPy-DS film and 175-cycled film was analyzed using a field emission gun scanning electron microscope (FEG-SEM, Zeiss, Supra 55). Fourier transform infrared (FTIR) spectra were recorded on VERTEX 70 spectrometer (BRUKER Co., USA) from 2000 to $650 \mathrm{~cm}^{-1}$ with a 4 $\mathrm{cm}^{-1}$ resolution. Ultraviolet-visible (UV-vis) spectra were recorded with a U-4001 spectrophotometer. The films used for FTIR and UV-vis were prepared on ITO coated glass slides and cycled under the same conditions as those on gold electrode of the quartz resonators.

\subsection{Electrogravimetric measurements}

All of the electrochemical experiments were carried out using an Autolab potentiostat-galvanostat electrochemical workstation (PGSTAT302). After the PPy-DS film electrogeneration, the $a c$-electrogravimetry cannot be conducted immediately because the film composition is not under equilibrium. So it was stabilized by 15 scan 
cycles from $-1.3 \mathrm{~V}$ to $0.5 \mathrm{~V} v s$. SCE at $50 \mathrm{mV} \cdot \mathrm{s}^{-1}$ in a $0.25 \mathrm{M} \mathrm{NaCl}$ aqueous electrolyte. This stabilized film was deemed as fresh film. Subsequently, ac-electrogravimetric investigation of fresh PPy film was performed at two different potentials $-0.6 \mathrm{~V}$ and -0.2 $\mathrm{V}$ vs. SCE, respectively. The ac-electrogravimetric measurements of the film were tracked after each $25 \mathrm{CV}$ cycles up until 175 cycles were reached, where the electrogravimetric response is too weak to be analyzed. The procedure is illustrated schematically in Figure 1 (a). Two key potentials were selected: $(i)-0.6$ V, located between the reduction $(-0.68 \mathrm{~V})$ and oxidation $(-0.5 \mathrm{~V})$ peak for fresh film and thus, can be regarded to be a representative potential of the Faradic process. (ii) $-0.2 \mathrm{~V}$, approximately a constant current response was observed for fresh film in the vicinity of this potential, therefore, it can be considered to be indicative of a non-Faradaic process. In order to have coherent comparison it is decided to keep monitoring the changes at these two potentials, even slight shifts of potential may occur during the electrochemical cycling.

For ac-electrogravimetry, a four-channel frequency response analyser (FRA, Solartron 1254) and a lab-made potentiostat (SOTELEM-PGSTAT) were used. The QCM was used under dynamic regime, the working electrode (WE) was polarized at previously selected potentials, and sinusoidal small amplitude potential perturbation $(80 \mathrm{mV} \mathrm{rms})$ was superimposed. The microbalance frequency change $\left(\Delta f_{\mathrm{m}}\right)$ related with the mass response $(\Delta m)$ of the modified working electrode was measured simultaneously with the charge response $(\Delta q)$ of the electrochemical system. The resulting signals were sent to the four-channel FRA, which allowed the electrogravimetric transfer function $\left(\frac{\Delta m}{\Delta E}(\omega)\right)$ and the charge/potential transfer function $\left(\frac{\Delta q}{\Delta E}(\omega)\right)$ to be obtained simultaneously at the 
given potential and frequency modulation, $f$ (pulsation $\omega=2 \pi f$ ). The charge/potential transfer function $\left(\frac{\Delta q}{\Delta E}(\omega)\right)$ and mass/potential transfer function $\left(\frac{\Delta m}{\Delta E}(\omega)\right)$ can be theoretically calculated by using the eq. (1), (2) and (3), where $\Delta c_{i}$ presents the change of the concentration of each species (ions and free solvent) in the film, $\omega$ the pulsation, $d_{f}$ the film thickness (here $200 \mathrm{~nm}$ estimated through QCM measurements), $K_{i}$ and $G_{i}$ are the partial derivatives of the flux $\left(J_{i}\right)$ with respect to the concentration and the potential, respectively. $K_{i}$ describes the kinetics of transfer. $G_{i}$ is the reciprocal of the transfer resistance $\left(R t_{i}\right)$, exhibiting the ease or difficulty in the transfer at the film/electrolyte interface for respective species.

$$
\begin{aligned}
& \frac{\Delta c_{i}}{\Delta E}(\omega)=\frac{G_{i}}{\left(j \omega d_{f}\right)+K_{i}} \\
& \frac{\Delta q}{\Delta E}(\omega)=F d_{f} \sum_{i} \frac{G_{i}}{\left(j \omega d_{f}\right)+K_{i}} \quad \text { (i: ions) } \\
& \frac{\Delta m}{\Delta E}(\omega)=-d_{f} \sum_{i} M_{i} \frac{G_{i}}{\left(j \omega d_{f}\right)+K_{i}} \quad \text { (i: ions and non-charged species) }
\end{aligned}
$$

On the basis of the above parameters, the characteristic frequency of transfer $\left(f_{i}\right)$, the transfer resistance $\left(R t_{i}\right)$ and the instantaneous capacitance $\left(C_{i}\right)$ of each species are further considered and calculated using eq. (4) to eq. (6).

$$
\begin{gathered}
f_{i}=\frac{K_{i}}{2 \pi d_{f}} \\
R t_{i}=\frac{\mp 1}{F G_{i}} \\
C_{i}=\frac{-F d_{f} G_{i}}{K_{i}}
\end{gathered}
$$

After the $a c$-electrogravimetry measurements, the experimental data obtained from fresh film, 100 and 175-cycled films were fitted with the theoretical functions given in eq. (2) 
and (3) by using the Mathcad software.

\subsection{Electroacoustic impedance measurements}

The viscoelastic properties of the PPy-DS film during electrochemical aging were explored through the electroacoustic admittance method. To track the viscoelastic variation of our films and to corroborate with the $a c$-electrogravimetry results, electroacoustic measurements were performed at the same stationary potentials $(-0.6 \mathrm{~V}$ and $-0.2 \mathrm{~V}$ ) after each 25 cycles up to the 175 th cycle was reached (Figure $1 \mathrm{~b}$ ). To perform the electroacoustic admittance measurements under polarization, an Agilent 4294A impedance analyzer associated to a lab-made potentiostat (SOTELEM-PGSTAT) was used.

A software developed in our laboratory (Simad) was used for fitting the experimental data for extracting the storage moduli $\left(G^{\prime}\right)$ and loss moduli $\left(G^{\prime \prime}\right)$ of the film. The real component $\left(G^{\prime}\right)$ describes the energy storage capability of the polymer chains and the imaginary part $\left(G^{\prime \prime}\right)$ is associated with the energy dissipation of the film due to irreversible deformation of polymer chains [38].

The complete theoretical electrical admittance, $Y_{t h}^{V}(\omega)$, of the loaded quartz resonator is:

$$
Y_{t h}^{V}(\omega)=\frac{1}{Z_{t h}^{V}(\omega)}=i \times \omega \times C_{p}+\frac{1}{Z_{m}^{V}(\omega)}
$$

where $\omega=2 \times \pi \times f, C p$ is the parasitic capacitance and $Z_{m}^{V}$ is the motional impedance of the loaded quartz resonator calculated with a viscoelastic model.

The motional impedance, $Z_{m}^{V}$, can be completely modelled according to the work of Martin et al. [39]. If the characteristics of the quartz and of the liquid are considered as constants, the motional electrical impedance, $Z_{m}^{V}$ of the coated resonator is: 


$$
Z_{m}^{V}(\omega)=\frac{h_{q}{ }^{2}}{4 \times e_{q}^{2} \times A} \times Z_{f} \times \frac{Z_{s}+Z_{f} \times \tanh \left(\theta_{f} \times h_{f}\right)}{Z_{f}+Z_{s} \times \tanh \left(\theta_{f} \times h_{f}\right)}
$$

where $h_{q}$ is the quartz thickness, $e_{q}$ is the quartz piezoelectric constant, $A$ is the active mass area, $Z_{f}$ is the acoustic impedance of the film, $Z_{s}$ is the acoustic impedance of the liquid, $\theta_{f}$ is the complex propagation constant of the film and $h_{f}$ is its thickness. Moreover, $Z_{f}$ and $\theta_{f}$ can be described as:

$$
\begin{gathered}
Z_{f}=\sqrt{\rho_{f} \times G_{f}} \\
\theta_{f}=\sqrt{\frac{\rho_{f}}{G_{f}}}
\end{gathered}
$$

where $\rho_{f}$ is the film density and $G_{f}$ is the shear thickness modulus of the film, which can be written as a complex number with a real and imaginary part, $G_{f}=G^{\prime}+j G^{\prime \prime}$, where $j^{2}=-1$.

The acoustic impedance of the solution, $Z_{s}$, is defined as eq. (9) except that $G^{\prime}$ becomes negligible and for a Newtonian liquid, $G^{\prime \prime}=2 \pi f \eta_{s}$, where $f$ is the frequency and $\eta_{s}$ the liquid viscosity.

\section{Results and discussion}

\subsection{Cyclic electrogravimetric behavior}

The cross-sectional morphology of electrodeposited PPy-DS films were observed by FEG-SEM (Figure 1c and 1d). The average film thickness is $\sim 130 \mathrm{~nm}$ and $\sim 110 \mathrm{~nm}$ for the fresh and 175-cycled film, respectively. These values correspond to the shrunken state of the film under the vacuum conditions of the measurements. Parallelly, the Sauerbrey equation was used to convert the microbalance frequency shift, $(\Delta f)$ to mass change $(\Delta m)$ during the PPy-DS electrodeposition [40]: $\Delta f=-\mathrm{C}_{f} \times \Delta m$, where $\mathrm{C}_{f}$ is the 
sensitivity factor of the quartz crystal resonator $\left(\mathrm{C}_{f}=18.3 \times 10^{7} \mathrm{~Hz} \cdot \mathrm{g}^{-1} \cdot \mathrm{cm}^{2}\right)$ and $\Delta m$ presents the film mass change per unit area. The estimated film thickness from the Sauerbrey equation is around $216 \mathrm{~nm}$ and $184 \mathrm{~nm}$ for the fresh and 175 -cycled films, respectively. An average film thickness of $200 \mathrm{~nm}$ is used for the fitting of the $a c$-electrogravimetric and electroacoustic data.

First of all, to explore the effect of electrochemical cycling on the electrochemical responses of the PPy-DS film, cyclic electrogravimetry (EQCM) was exploited to follow the current and the simultaneous mass responses as a function of the electrochemical cycling in aqueous $0.25 \mathrm{M} \mathrm{NaCl}$. The two anodic peaks of fresh film in Fig.2a are likely to be related to creation of the polarons and bipolarons in agreement with the previous works $[41,42]$ without any clear attribution of each peak to either of them. Alternately, reference 27 and 42 have reported indications that the first oxidation peak I at $-0.5 \mathrm{~V}$ and the second oxidation peak II at $0.3 \mathrm{~V}$ are related to cations and anions' transfer, respectively. As shown in Figure 2a, the redox peaks progressively disappear and the shape of $\mathrm{CV}$ curves tends to become quasi rectangular. This observation indicates the fading of the pseudocapacitive capability and/or an increase in the contribution of capacitive response to the charge compensation process. In spite of the fairly clear $\mathrm{CV}$ responses, the evolution of the mass response (Figure 2b) during cycling is rather complex. For a fresh film, a mass increase and a decrease were observed during the reduction and the oxidation process, respectively. After 100 cycles, the global mass response has been significantly decreased suggesting the presence of either smaller mass changes of the film or different flux directions of the species participating in the charge compensation process. After the film was cycled 175 times, the mass response displayed an opposite behavior relative to that of fresh film, i.e., mass 
decrease during reduction and mass ingress during oxidation. Therefore, from a global point of view, it can be suggested that the fresh film experiences cation insertion and expulsion during reduction and oxidation, respectively, whereas the 175 times-cycled film undergoes anion expulsion during reduction and insertion during oxidation. Concerning the 100 times-cycled film, both cations and anions can participate in the charge compensation and they may play an equal part in the electrochemical response without consideration of solvent exchange. Thus, the mass contribution from cations and anions may offset which leads to this almost "no mass response" for 100-cycled film, which is illustrated in Figure 2c-zone II.

The maximum mass change $\left(M_{\max }\right)$ during a redox cycle was tracked after every 25 scan cycles, as depicted in Figure 2c. The $M_{\max }$ value of the film decreases and reaches to a minimum after 100 cycles, i.e. $0.23 \mu \mathrm{g} . \mathrm{cm}^{-2}$, which is approximately 7 times less than that of a fresh film. After that, $M_{\max }$ values gradually increase to $1.4 \mu \mathrm{g} . \mathrm{cm}^{-2}$ for 175-cycled film. This "quasi-U" shape describes an obvious transition where the predominance of cation participation is gradually replaced by anion participation in the charge compensation process as the film is electrochemically cycled.

The above discussion considers the ionic species as the major contribution but the free solvent contributions cannot be excluded. It has been widely reported that the ion exchanges during redox reactions are commonly accompanied with flux of solvent [43, 44]. To get insights into the nature of the ionic species and possible free solvent molecules' contribution, the EQCM results are further analyzed. The molar mass, $M_{i}$, of each species involved in the charge compensation process can provide a better understanding of the species transfer as a function of the number of cycles. 
To do this, the $F \frac{\Delta m}{\Delta q}$ function was calculated as a function of applied potential using the current and the mass response of the film (Figure $2 \mathrm{a}$ and $\mathrm{b}$ ), as follows:

$$
M_{i}=F \frac{d m}{d q}=F\left(\frac{d m}{d t}\right) \cdot \frac{1}{i}
$$

This function provides a global estimation of the molar mass of the species $\left(M_{i}\right)$ that may participate in the charge compensation process. The $F \frac{\Delta m}{\Delta q}$ function was calculated from the reduction branch of the EQCM data and Figure $2 \mathrm{~d}$ compares $M_{i}$ of the species involved in the reduction process as the film is electrochemically cycled. It is evident that $M_{i}$ presents a potential and cycling dependence. For fresh film, $M_{i}$ exhibits a negative value reaching -88 g. $\mathrm{mol}^{-1}$ at $-0.7 \mathrm{~V}$ without an evident plateau in the reduction sweep regime. It should be kept in mind that the ions present in the electrolyte are only sodium cations $\left(\mathrm{Na}^{+}, 23\right.$ g.mol $\left.{ }^{-1}\right)$ and chloride anions $\left(\mathrm{Cl}^{-}, 35.5\right.$ g.mol $\left.{ }^{-1}\right)$. In the $F \frac{\Delta m}{\Delta q}$ function, negative and positive values are characteristic of cations and anions, respectively $[28,43]$. The values higher than expected molar mass of the cations suggest that cations are inserted into the fresh film accompanied with water in either free form with the same flux direction or in the hydration shell of $\mathrm{Na}^{+}$. After the film is 100 times-cycled, the potential corresponding to the max $M_{i}$ value is moved to more cathodic potential (from $-0.7 \mathrm{~V}$ to $-1.05 \mathrm{~V}$ ). When the film is further cycled up to 175 cycles, the peak intensity dramatically increases approximately 5 times up to 479 g. $\mathrm{mol}^{-1}$ compared to that observed after 100 times cycling. This indicates that the nature of the species involved in the charge compensation are dependent on the film cycling state. The film exhibits unexpected behavior: the cations dominate charge balance when the film is fresh, while anion's contribution increases as the film is electrochemically 
cycled and predominates in charge balance in the end. Since the estimated molar mass values are much higher than the theoretical ones $\left(\mathrm{Na}^{+}, 23 \mathrm{~g} \cdot \mathrm{mol}^{-1}\right.$ and $\left.\mathrm{Cl}^{-}, 35.5 \mathrm{~g} \cdot \mathrm{mol}^{-1}\right)$, the water molecules are speculated to play a significant role in the electrochemical process.

However, it is not straightforward to separate each species contribution and the possible synergistic effect among them. Indeed, the deconvolution of the global cyclic electrogravimetry response into gravimetric and dynamic components is quite challenging since the measurements are done at a certain scan rate. Therefore, coupling of the QCM with electrochemical impedance spectroscopy ( $a c$-electrogravimetry) was suggested [27]. To shed light on the subtleties of the charge compensation process during electrochemical aging, an ac-electrogravimetric study was performed to understand the relationship between film cycling and charge compensation process.

\subsection{Ac-electrogravimetric investigations}

To gain insights into the dynamic behavior of the species transfer at the film/electrolyte interface at the temporal scale, ac-electrogravimetry was performed to probe the influence of film cycling on the transfer of charged and non-charged species. Figure 3 compares the charge/potential transfer function $\frac{\Delta q}{\Delta E}(\omega) \mathrm{TF}$, obtained at $-0.6 \mathrm{~V}$ and $-0.2 \mathrm{~V}$ at different cycled state of the film, respectively.

Theoretically, the $\frac{\Delta q}{\Delta E}(\omega)$ TF in Figure 3 appears as a single loop if there is only one charged species transferred. In this study, the $\frac{\Delta q}{\Delta E}(\omega)$ TF shows mainly one suppressed loop (a composition of several loops) at both potentials at different cycled state of the film, suggesting the presence of more than one species participating in the charge 
compensation. It is also likely that their time constants are not significantly different to have them appear as separate loops. The experiment data were fitted using theoretical equation 2 and two ionic species were involved. Their corresponding values of $K_{i}$ and $G_{i}$, obtained through the fitting process are given in Table 1. As the film is electrochemically cycled, the diameter of the global loop gets smaller, which may indicate that the population of the ions involved in the charge compensation is reduced as clearly shown in figure $3 \mathrm{~g}$ and $\mathrm{h}$ for both potentials. This result is coherent with the decrease of the current observed in Figure 2a.

Apart from the charge/potential TF, the electrogravimetric response, $\frac{\Delta m}{\Delta E}(\omega)$, which can provide information on both the charged and non-charged species transfer, was simultaneously obtained (Figure 4). For all $\frac{\Delta m}{\Delta E}(\omega)$ fittings (except Figure 4f), three species, $\mathrm{Na}^{+}$(hydrated or not), free water molecules and $\mathrm{Cl}^{-}$were identified, which led to a good agreement between the experimental and theoretical curves. Our data presented in Figure 4 indicate that the cations appear at high frequencies, followed by free water molecules at intermediate frequencies and anions at low frequencies, independently of the cycled degree of the film at both potentials. At $-0.2 \mathrm{~V}$, the electrogravimetric response is rather constant and only desolvated sodium at high frequencies, free water contribution at intermediate frequencies and chloride at low frequencies were detected (Figure $4 \mathrm{a}, \mathrm{c}$ and e). At $-0.6 \mathrm{~V}$, a fairly good agreement between the experimental and theoretical $\frac{\Delta m}{\Delta E}(\omega)$ data was obtained by considering the molar mass of hydrated cations $\left(\mathrm{Na}^{+} \cdot 2 \mathrm{H}_{2} \mathrm{O}\right)$ for fresh film (Figure $4 b$ ). It seems that the solvation shell of the $\mathrm{Na}^{+}$is gradually removed at $-0.6 \mathrm{~V}$ as the film is electrochemically 
cycled (Figure $4 \mathrm{~d}$ and $\mathrm{f}$ ). It is interesting to note that a small loop appears in the first quadrant at very high frequencies for the 175-cycled film (Figure 4f). It is supposed that some of the $\mathrm{DS}^{-}$anions anchored on the polymer chains are removed and start to participate in the charge compensation process, as the molar mass of $\mathrm{DS}^{-}$was determined. This is probably related to the periodic swelling-shrinking process of the film cycling which modifies the film structure and permits the exchange of DS ${ }^{-}$. It will be further explored in the electroacoustic part (3.3).

The $\frac{\Delta m}{\Delta E}(\omega)$ TFs at both potentials for all cycled films (Figure $4 \mathrm{~g}$ and $\mathrm{h}$ ) present one big loop in the third quadrant at high and intermediate frequencies (HF and IF), and another one in the fourth quadrant at lower frequencies (LF). It is worth mentioning here that the loops in the third quadrant are characteristic of contributions originated from cations and/or free solvent with the same flux direction as cations [27].These loops in the third quadrant are reduced in diameter as the film is electrochemically cycled (Figure 4 (a-e)) which indicates either a decrease of the cation/free solvent contributions or a decrease of the molar mass of the cations by losing their solvation shell.

The characteristic frequencies, $f_{i}$, in Figure 5(a) and (b) display that cations (hydrated or not) have the highest kinetics of transfer at the electrode/electrolyte interfaces, followed subsequently by $\mathrm{H}_{2} \mathrm{O}$ molecules and $\mathrm{Cl}^{-}$anions $\left(f_{c}>f_{s}>f_{a}\right)$ at both potentials as the film is electrochemically cycled. Additionally, it is noted that only for the 175 -cycled film at $-0.6 \mathrm{~V}$, the $\mathrm{DS}^{-}$anions are observed in the charge compensation process where they possess the highest kinetics of transfer $\left(\mathrm{DS}^{-}\right.$anions were not taken into account in Figure $5 \mathrm{~b}, \mathrm{~d}$ and $\mathrm{f}$ as they are only detected for 175 -cycled film at $-0.6 \mathrm{~V}$ ).

At $-0.2 \mathrm{~V}$ (Figure 5a), the $f_{i}$ of $\mathrm{H}_{2} \mathrm{O}$ molecules is enhanced nearly 3 times up to $1.75 \mathrm{~Hz}$ 
in the region II, accompanied with a decrease in cation transfer kinetics (from $3.45 \mathrm{~Hz}$ to $2.15 \mathrm{~Hz}$ ). When the film is electrochemically cycled up to region III, the $f_{i}$ value of the cation and solvent molecules approaches and they eventually exhibit equivalent transfer kinetics. The transfer of anions remain as the slowest contribution at both potentials over the course of film cycling, which is in agreement with the higher $R_{t}$ value of anions compared to that of cations and water molecules, as shown in Figure 5c.

On the contrary, the cation transfer kinetics become faster in the end of region II at $-0.6 \mathrm{~V}$ (Figure $5 \mathrm{~b}$ ), which can be attributed to the dehydration process of hydrated cations $\left(\mathrm{Na}^{+} \cdot 2 \mathrm{H}_{2} \mathrm{O}\right)$ on the course of film cycling as depicted in Figure 6a. Meanwhile, it also demonstrates higher transfer capability of dehydrated $\mathrm{Na}^{+}$relative to the hydrated counterparts due to its smaller size.

An interesting phenomenon is observed in the transfer of $\mathrm{H}_{2} \mathrm{O}$ molecules at $-0.6 \mathrm{~V}$ (Figure 5b) as follows. The $f_{i}$ of $\mathrm{H}_{2} \mathrm{O}$ molecules experience a slight decrease (from $0.90 \mathrm{~Hz}$ to $0.35 \mathrm{~Hz}$ ) in region $\mathrm{I}$, followed by a surge up to $3.9 \mathrm{~Hz}$ at the beginning of region II. Afterwards, it progressively decreases to $0.21 \mathrm{~Hz}$ at the end of region III. Correspondingly, the $R_{t}$ of $\mathrm{H}_{2} \mathrm{O}$ molecules (Figure 5d) shows an approximate mirror symmetry, except that the peak value of $f_{i}$ is reached after 75 cycles whereas the minimum value of $R_{t}$ appears after 125 cycles (i.e. $\sim 50$ cycles lag between the $f_{i}$ and $R_{t}$ ). In fact, this is not contradictory because the $f_{i}$ is related with the transfer kinetics of the species, while the $R_{t}$ is correlated to the ease/difficulty of their transfer. As the film is 75 times-cycled, the hydration shell of cations becomes smaller (one $\mathrm{H}_{2} \mathrm{O}$ molecule removed), and the cation motion is somewhat released from the restriction of $\mathrm{H}_{2} \mathrm{O}$ shell, resulting in an increase of $f_{c}$. Meaningwhile, much more steric spaces inside the film would become accessible for free $\mathrm{H}_{2} \mathrm{O}$ molecules due to the smaller size of cations. This 
can lead to an ease in the solvent transfer which is translated into a decrease of $R_{t}\left(\mathrm{H}_{2} \mathrm{O}\right)$ values. After that, the cations completely remove their hydration shell towards the 125 times-cycled state (the end of region II), i.e. bare cations (Figure 6a). Due to the relatively smaller size of bare cations, free $\mathrm{H}_{2} \mathrm{O}$ molecules inside the film may be better accommodated leading to a minimum of $R_{t}\left(\mathrm{H}_{2} \mathrm{O}\right)$ value observed at around 125 cycles (Figure $5 \mathrm{~d}$ ). In this case, $\mathrm{H}_{2} \mathrm{O}$ molecules possess the greatest potential to be transferred at the film/electrolyte interface, which can be further confirmed in Figure $6 \mathrm{~b}$. For the measurements at $-0.6 \mathrm{~V}$, the proportion of free $\mathrm{H}_{2} \mathrm{O}$ transferred through the film/electrolyte interface (calculated using eq. 12 and 13) reaches maximum at the end of region II, i.e. $80 \%$ after 125 cycles (Figure 6b). This observation can be discussed by consideration of an increased amount of space available inside the film provided by the dehydration process of the cations in region II. This results in a minimum value of the $R t_{s}$ lagging behind $\sim 50$ cycles to the peak of $f_{s}$ (Fig. $5 \mathrm{~b}$ and $5 \mathrm{~d}$ ). Additionally, the film at $-0.6 \mathrm{~V}$ undergoes more $\mathrm{H}_{2} \mathrm{O}$ exchange than that at $-0.2 \mathrm{~V}$ for the major portions of the cycling period (Figure 6b). This finding may indicate a relatively higher swollen state and porosity of the film when polarized at $-0.6 \mathrm{~V}$. It can facilitate the transfer of bigger ions and may be the reason for (i) the transfer of hydrated cations $\left(\mathrm{Na}^{+} \cdot 2 \mathrm{H}_{2} \mathrm{O}\right)$ at $-0.6 \mathrm{~V}$ rather than at $-0.2 \mathrm{~V}$ as the film is electrochemically cycled in region I, and (ii) the transfer of bigger anions $\left(\mathrm{DS}^{-}\right)$after the film is cycled $\sim 175$ times.

$$
\mathrm{H}_{2} \mathrm{O}(\text { free })=\frac{\left|\frac{-G_{\mathrm{H}_{2} \mathrm{O}}}{K_{\mathrm{H}_{2} \mathrm{O}}}\right|}{\left|\frac{-G_{\mathrm{H}_{2} \mathrm{O}}}{K_{\mathrm{H}_{2} \mathrm{O}}}\right|+\left|\frac{-G_{\mathrm{Na}^{+}}}{K_{\mathrm{Na}^{+}}}\right|+\left|\frac{-G_{\mathrm{Na}^{+}+x \mathrm{H}_{2} \mathrm{O}}}{K_{\mathrm{Na}^{+}+x \mathrm{H}_{2} \mathrm{O}}}\right|+\left|\frac{-G_{\mathrm{Cl}^{-}}}{K_{C l^{-}}}\right|}
$$




$$
\mathrm{H}_{2} \mathrm{O}(\text { global })=\frac{\left|\frac{-G_{\mathrm{H}_{2} \mathrm{O}}}{K_{\mathrm{H}_{2} \mathrm{O}}}\right|+x\left|\frac{-G_{\mathrm{Na}^{+}+x \mathrm{H}_{2} \mathrm{O}}}{K_{\mathrm{Na}^{+}+x \mathrm{H}_{2} \mathrm{O}}}\right|}{\left|\frac{-G_{\mathrm{H}_{2} \mathrm{O}}}{K_{\mathrm{H}_{2} \mathrm{O}}}\right|+\left|\frac{-G_{\mathrm{Na}^{+}}}{K_{\mathrm{Na}^{+}}}\right|+\left|\frac{-G_{\mathrm{Na}^{+}+x \mathrm{H}_{2} \mathrm{O}}}{K_{\mathrm{Na}^{+}+x \mathrm{H}_{2} \mathrm{O}}}\right|+\left|\frac{-G_{\mathrm{Cl}^{-}}}{K_{\mathrm{Cl}^{-}}}\right|}
$$

The $R t_{i}$ and $C_{i}$ (instantaneous capacitance) of cations and anions $\left(\mathrm{Cl}^{-}\right.$, without consideration of $\mathrm{DS}^{-}$) possess a similar dependence on the electrochemical cycling (Figure $5 \mathrm{c}-\mathrm{f}$ ). When the data obtained at $-0.2 \mathrm{~V}$ is taken as an example, the $R t_{i}$ of ions shows a progressive increase with electrochemical cycling, indicating that the more the film is cycled, the more difficult the ionic transfer becomes. Accordingly, the ionic capacitance, $C_{i}$ decreases for both cations and anions. This observation may indicate that transfer process of ions progressively degrades. Hence, it can be suggested that the periodic charging-discharging process can weaken the capability of CPEs to exchange ions at the film/electrolyte interface as a function of cycle number.

\subsection{Viscoelastic property changes upon film aging}

Numerous studies have reported that the viscoelastic properties of the electroactive polymer play a crucial role in the electrogravimetric response if the film is not sufficiently thin or rigid [45]. More importantly, the viscoelastic change with electrochemical cycling is supposed to have a great influence on the electrochemical performance of the film primarily because volumetric changes during the redox process (insertion or expulsion of charged and non-charged species) are strongly associated with the viscoelastic properties of the polymer chains. Thus, the variation of the viscoelastic properties of the film during electrochemical cycling process was examined and the correlation between electrochemical and viscoelastic properties was further considered with regard to long term performance of CPEs. 
Figure 7 a displays a similar change of $G^{\prime}$ and $G^{\prime \prime}$ at the two selected potentials. Taking the film measured at $-0.6 \mathrm{~V}$ for example, the storage modulus $\left(G^{\prime}\right)$ is increased by approximately $200 \%$ as the film is electrochemically cycled. However, $G^{\prime \prime}$ shows an entirely opposite tendency with film cycling, decreasing from $0.77 \times 10^{5} \mathrm{~N} . \mathrm{m}^{-2}$ to $0.19 \times 10^{5} \mathrm{~N} . \mathrm{m}^{-2}$ at $-0.6 \mathrm{~V}$. It has been revealed that the $G^{\prime}$ is correlated with the film stiffness, while $G^{\prime \prime}$ is a measure of the film viscosity $[12,38]$. The progressively increased $G^{\prime}$ and decreased $G^{\prime \prime}$ suggest that the periodical cycling renders the PPy-DS film stiffer and less viscous. Nevertheless, this should not be attributed to the overoxidation of PPy because it starts at potentials greater than $0.7 \mathrm{~V}$ vs. SCE $[46,47]$. Additionally, FTIR spectra of the fresh and cycled PPy-DS films (Fig. S1 in supporting information) exhibit the characteristic vibrational bands associated with the doped polypyrrole structure. The spectra of the fresh, 100- and 175-cycled film do not show remarkable differences which suggests the absence of polymer crosslinking phenomena upon electrochemical cycling. The absence of a band at $\sim 1700 \mathrm{~cm}^{-1}$ (corresponding to $\mathrm{C}=\mathrm{O}$ functions) further indicates that there is no overoxidation of the polymer film [48].

In this work, we hold that the reconformation of the polymer chains resulted from cycling process embows the film more rigid (increased $G$ ) and less viscous (decreased $\left.G^{\prime \prime}\right)$. It has been reported that the requirement of co-planarity of $\pi$ orbitals for long conjugation leads to the stiffness of poly (3-alkylthiophene)s through the reconfiguration and rearrangements of polymer chains [32]. Briefly, redox process of PPy-DS films involves a sequence of events: (i) electrons transferred between the film and the working electrode, (ii) exchange of cations and/or anions between the film and electrolyte to satisfy electroneutrality which is often coupled with free solvent transfer to meet the volumetric confinement of the viscoelastic film and lastly, (iii) 
reconformation of polymer chains to be compatible with such new spatial architecture of the film. In a redox process, PPy chain's reconformation takes place to keep sufficient $\pi$ orbital overlaps for conduction structure, where a co-planarity of $\pi$ orbitals is required within $40^{\circ}$ [49]. Therefore, upon electrochemical cycling process, the structure of the polymer chains can be progressively altered due to such conformational changes. Specifically, for fresh PPy-DS film, pyrrole rings possess a coplanar conformation [47], and the movement of $\mathrm{DS}^{-}$ions is greatly restricted by strong interactions from large conjugated $\pi$ systems. During film cycling process, the coplanar conformation of PPy is gradually forced to approach a non-coplanar one by means of PPy chain's motions, giving rise to a progressive deterioration of long conjugated systems and consequently loss of electroactive sites or electronic conductivity, as it is approved by the fading electrical response of cyclic voltammetry in Figure 2a or charge/potential TF in Figure $3 \mathrm{~g}$ and $\mathrm{h}$. When the film is further electrochemically cycled (175 cycles), the $\mathrm{DS}^{-}$ions are released out of the film and embark on the charge compensation process, as supported by Figure 4f. Altogether, the electrochemical cycling process causes the reconformation of the polymer chains, which brings about the stiffness of the film with fading electronic conductivity.

The film loss tangent, $G^{\prime \prime} / G^{\prime}$ was further used for describing the viscoelastic evolution of the film upon cycling process. As depicted in Figure $7 b$, the film loss tangent shows a comparable decrease upon cycling at the two different potentials. It indicates that the cycling process confers increasing stiffness on the film. Namely, region I can be generally regarded as viscous region, region II becomes viscoelastic while region III is fairly elastic in the film electrochemical cycling evolution.

The stiffness of the film can restrict the volumetric changes and make it more 
difficult for ionic species not only to be transferred at the film/electrolyte interface but transported in the film bulk as well, which is in agreement with results obtained from the cyclic electrogravimetric and ac-electrogravimetric part, i.e. i) fading of the pseudocapacitive capability $i$ ) increase of the ionic transfer resistance, $R t_{\text {i }}$, and $i i i$ ) decrease of the instantaneous capacitance, $C_{i}$, of each charged species.

As a matter of fact, the volume of the PPy-DS film can be varied from cathodic to anodic potentials within one cycle (Figure 8-Route I) and also at the same potential after many cycles (Figure 8-Route II). As Figure 8-Route I shows, the PPy-DS film undergoes successive swelling and shrinking cycles during the redox process. In addition, a dehydration process of cations for freshly prepared films has been reported during anodic potential sweep due to the lower porosity of PPy-DS film in a relatively shrunken state [38]. As for route II which is explored in this work, the volumetric change capability of the film can become poorer upon cycling, and the solvation shell of cation at $-0.6 \mathrm{~V}$ is removed during the cycling process. Figure 8 elucidates the two different ways which can stiffen the PPy-DS film, i.e. anodic sweep and film cycling, both of which prohibit the transfer of hydrated $\mathrm{Na}^{+}$. On the course of electrochemical cycling, the film would hardly experience volumetric change any more, which is accompanied with a fading of the electrochemical performance as seen in CV responses (Figure 2a) and charge/potential response (Figure $3 \mathrm{~g}$ and $\mathrm{h}$ ). The electrochemical activity loss upon cycling is further investigated by UV-vis spectroscopy. Figure S2 in supporting information indicates the presence of a distinct band appearing below $\sim 480$ $\mathrm{nm}$ which is due to $\pi-\pi^{*}$ transitions [50]. When the PPy-DS films are cycled for 100 and 175 times, a decrease of the intensity and a shift to lower wavelength values of this characteristic band are observed. A blue shift and a decrease in the intensity of this band 
indicate an increase in the band gap of the PPy-DS films and a decrease in the conjugation length of the conducting polymer upon electrochemical cycling. This observation is in agreement with (i) the cyclic voltammetry investigations showing a considerable electrochemical activity loss and (ii) with the viscoelastic property investigations indicating a stiffening of the polymer which is likely to render the charge transfer more difficult. To the best of authors' knowledge, it is the first time that the correlation between electrochemical and viscoelastic properties in an electrochemical cycling process has been systematically investigated.

\section{Conclusions}

The combination of EQCM, ac-electrogravimetry and electroacoustic measurements was proposed to track the electrochemical and viscoelastic evolution during the electrochemical cycling of PPy-DS films. An obvious ion-selective transition from cations to anions for charge compensation is observed during film cycling process. A predominant role is played by cations for fresh and slightly cycled films, whereas anions dominate the charge balance in older films.

The electrochemical performance was investigated at two different potentials. At $-0.6 \mathrm{~V}$, the film presents a relatively more swollen state than that at $-0.2 \mathrm{~V}$ due to the higher amount of $\mathrm{H}_{2} \mathrm{O}$ molecules insertion, facilitating the transfer of bigger ions, i.e., $\mathrm{Na}^{+}$with two $\mathrm{H}_{2} \mathrm{O}$ molecules in the hydration shell and $\mathrm{DS}^{-}$anions. Kinetics of $\mathrm{H}_{2} \mathrm{O}$ molecule in region II (50-125th cycle in Figure 5b) show a complex and cycling-dependent property due to the competitive relationship between availability for accommodation inside the film provided by cation's dehydration process (favoring $\mathrm{H}_{2} \mathrm{O}$ transfer) and polymer chain's increasing stiffness during film cycling (increased $G^{\prime}$, 
prohibiting $\mathrm{H}_{2} \mathrm{O}$ transfer). At $-0.2 \mathrm{~V}$, desolvated $\mathrm{Na}^{+}$is the only form of cations participating in the charge compensation. The cation is the fastest species (except the $\mathrm{DS}^{-}$at $-0.6 \mathrm{~V}$ for 175 -cycled film) transferred at the film/electrolyte interface followed by free $\mathrm{H}_{2} \mathrm{O}$ molecules at intermediate frequencies and anions are the slowest species at both potentials irrespective of cycled degree of the film.

For PPy-DS electrodes, the ionic transfer becomes more difficult upon electrochemical cycling process examined in the present work. It should be noted that this evolution can also be influenced by the film thickness, the nature and the concentration of electrolytes, and the scan rate. The observed ionic transfer change is not only due to the loss of electroactive sites inside the film but also due to the increasing stiffness of the polymer chains. It is attributed to the reconformation of the PPy chains which consequently result in the deterioration of the conjugated $\pi$ systems. This study presents an example showing the utility of complementary electrochemical methods to investigate the correlation between electrochemical performance and viscoelastic variations of PPy-DS electrodes upon cycling. The suggested diagnostic strategy can be applied to other CPEs and may help to develop new synthetic strategies for designing highly efficient electrodes in energy devices with improved performance.

\section{AUTHOR INFORMATION}

\section{Corresponding Author}

* E-mail addresses: ozlem.sel@upmc.fr (O. Sel), hubert.perrot@upmc.fr (H. Perrot).

\section{Notes}

The authors declare no competing financial interest. 


\section{Acknowledgments}

Wanli Gao acknowledges China Scholarship Council (CSC) for Ph.D. grant. F. Pillier is thanked for the FEG-SEM measurement.

\section{References}

[1] O. Knopfmacher, M.L. Hammock, A.L. Appleton, G. Schwartz, J. Mei, T. Lei, J. Pei, Z. Bao, Highly stable organic polymer field-effect transistor sensor for selective detection in the marine environment, Nat. Commun. 5 (2014) 2954.

[2] A. Ramanavičius, A. Ramanavičienè, A. Malinauskas, Electrochemical sensors based on conducting polymer-polypyrrole, Electrochim. Acta 51 (2006) 6025.

[3] R. Gracia, D. Mecerreyes, Polymers with redox properties: materials for batteries, biosensors and more, Polym. Chem. 4 (2013) 2206.

[4] F.S. Li, Y.S. Wu, J. Chou, M. Winter, N.L. Wu, A mechanically robust and highly ion-conductive polymer-blend coating for high-power and long-life lithium-ion battery anodes, Adv. Mater. 27 (2015) 130.

[5] K. Wang, H. Wu, Y. Meng, Z. Wei, Conducting polymer nanowire arrays for high performance supercapacitors, Small 10 (2014) 14.

[6] H.R. Ghenaatian, M.F. Mousavi, M.S. Rahmanifar, High performance hybrid supercapacitor based on two nanostructured conducting polymers: Self-doped polyaniline and polypyrrole nanofibers, Electrochim. Acta 78 (2012) 212.

[7] L. Han, P. Tang, L. Zhang, Hierarchical Co3O4@PPy@MnO2 core-shell-shell nanowire arrays for enhanced electrochemical energy storage, Nano Energy 7 (2014) 42.

[8] T. Liu, L. Finn, M. Yu, H. Wang, T. Zhai, X. Lu, Y. Tong, Y. Li, Polyaniline and polypyrrole pseudocapacitor electrodes with excellent cycling stability, Nano Lett. 14 (2014) 2522.

[9] R. Holze, Y.P. Wu, Intrinsically conducting polymers in electrochemical energy technology: Trends and progress, Electrochim. Acta 122 (2014) 93.

[10] C. Xia, W. Chen, X. Wang, M.N. Hedhili, N. Wei, H.N. Alshareef, Highly Stable Supercapacitors with Conducting Polymer Core-Shell Electrodes for Energy Storage Applications, Adv. Energy Mater. 5 (2015) 1401805.

[11] J. Agrisuelas, C. Gabrielli, J.J. García-Jareño, H. Perrot, O. Sel, F. Vicente, Viscoelastic potential-induced changes in acoustically thin films explored by quartz crystal microbalance with motional resistance monitoring, Electrochim. Acta 176 (2015) 1454.

[12] M.A. Mohamoud, A.R. Hillman, The effect of anion identity on the viscoelastic properties of polyaniline films during electrochemical film deposition and redox cycling, Electrochim. Acta 53 (2007) 1206.

[13] N. Shpigel, M.D. Levi, S. Sigalov, O. Girshevitz, D. Aurbach, L. Daikhin, N. Jackel, V. Presser, Non-invasive in situ dynamic monitoring of elastic properties of 
composite battery electrodes by EQCM-D, Angew. Chem. Int. Ed. 54 (2015) 12353.

[14] G. Wang, L. Zhang, J. Zhang, A review of electrode materials for electrochemical supercapacitors, Chem. Soc. Rev. 41 (2012) 797.

[15] L. Zhan, Z. Song, J. Zhang, J. Tang, H. Zhan, Y. Zhou, C. Zhan, PEDOT: Cathode active material with high specific capacity in novel electrolyte system, Electrochim. Acta 53 (2008) 8319.

[16] D. Mo, W. Zhou, X. Ma, J. Xu, D. Zhu, B. Lu, Electrochemical synthesis and capacitance properties of a novel poly(3,4-ethylenedioxythiophene bis-substituted bithiophene) electrode material, Electrochim. Acta 132 (2014) 67.

[17] H. Feng, B. Wang, L. Tan, N. Chen, N. Wang, B. Chen, Polypyrrole/hexadecylpyridinium chloride-modified graphite oxide composites: Fabrication, characterization, and application in supercapacitors, J. Power Sources 246 (2014) 621.

[18] H. Tang, J. Wang, H. Yin, H. Zhao, D. Wang, Z. Tang, Growth of polypyrrole ultrathin films on $\operatorname{MoS}(2)$ monolayers as high-performance supercapacitor electrodes, Adv. Mater. 27 (2015) 1117.

[19] G. Inzelt, V. Kertesz, A.-S. Nyback, Electrochemical quartz crystal microbalance study of ion transport accompanying charging-discharging of poly(pyrrole) films, J. Solid State Electrochem. 3 (1999) 251.

[20] L. Wang, X. Feng, L. Ren, Q. Piao, J. Zhong, Y. Wang, H. Li, Y. Chen, B. Wang, Flexible Solid-State Supercapacitor Based on a Metal-Organic Framework Interwoven by Electrochemically-Deposited PANI, J. Am. Chem. Soc. 137 (2015) 4920.

[21] R.B. Ambade, S.B. Ambade, N.K. Shrestha, Y.C. Nah, S.H. Han, W. Lee, S.H. Lee, Polythiophene infiltrated $\mathrm{TiO} 2$ nanotubes as high-performance supercapacitor electrodes, Chem. Commun. 49 (2013) 2308.

[22] G.A. Snook, P. Kao, A.S. Best, Conducting-polymer-based supercapacitor devices and electrodes, J. Power Sources 196 (2011) 1.

[23] C. Zhou, Y. Zhang, Y. Li, J. Liu, Construction of high-capacitance 3D CoO@polypyrrole nanowire array electrode for aqueous asymmetric supercapacitor, Nano Lett. 13 (2013) 2078.

[24] F. Escobar-Teran, A. Arnau, J.V. Garcia, Y. Jiménez, H. Perrot, O. Sel, Gravimetric and dynamic deconvolution of global EQCM response of carbon nanotube based electrodes by Ac-electrogravimetry, Electrochem. Commun. 70 (2016) 73.

[25] J.M. Griffin, A.C. Forse, W.Y. Tsai, P.L. Taberna, P. Simon, C.P. Grey, In situ NMR and electrochemical quartz crystal microbalance techniques reveal the structure of the electrical double layer in supercapacitors, Nat. Mater. 14 (2015) 812.

[26] W.Y. Tsai, P.L. Taberna, P. Simon, Electrochemical quartz crystal microbalance (EQCM) study of ion dynamics in nanoporous carbons, J. Am. Chem. Soc. 136 (2014) 8722.

[27] C. Gabrielli, J.J. Garcia-Jareno, M. Keddam, H. Perrot, F. Vicente, Ac-electrogravimetry study of electroactive thin films. II. Application to polypyrrole, J. Phys. Chem. B 106 (2002) 3192.

[28] L.T.T. Kim, C. Gabrielli, A. Pailleret, H. Perrot, Correlation between ion-exchange properties and swelling/shrinking processes in hexasulfonated calix[6]arene doped polypyrrole films: ac-electrogravimetry and electrochemical atomic force microscopy investigations, Electrochim. Acta 56 (2011) 3516.

[29] M.D. Levi, G. Salitra, N. Levy, D. Aurbach, J. Maier, Application of a 
quartz-crystal microbalance to measure ionic fluxes in microporous carbons for energy storage, Nat. Mater. 8 (2009) 872.

[30] S. Patrice, G. Yury, Materials for electrochemical capacitors, Nat. Mater. 7 (2008) 845.

[31] J.J. García-Jareño, C. Gabrielli, H. Perrot, Validation of the mass response of a quartz crystal microbalance coated with Prussian Blue film for ac electrogravimetry, Electrochem. Commun. 2 (2000) 195.

[32] A.R. Hillman, I. Efimov, M. Skompska, Dynamics of regioregular conducting polymer electrodes in response to electrochemical stimuli, Faraday Discuss. 121 (2002) 423.

[33] S. Koehler, A. Bund, I. Efimov, Shear moduli of anion and cation exchanging polypyrrole films, J. Electroanal. Chem. 589 (2006) 82.

[34] A.R. Hillman, M.A. Mohamoud, I. Efimov, Time-temperature superposition and the controlling role of solvation in the viscoelastic properties of polyaniline thin films, Anal. Chem. 83 (2011) 5696.

[35] A. Ispas, R. Peipmann, A. Bund, I. Efimov, On the p-doping of PEDOT layers in various ionic liquids studied by EQCM and acoustic impedance, Electrochim. Acta 54 (2009) 4668.

[36] V. Lyutov, V. Gruia, I. Efimov, A. Bund, V. Tsakova, An acoustic impedance study of PEDOT layers obtained in aqueous solution, Electrochim. Acta 190 (2016) 285.

[37] C. Gabrielli, J.J. Garcia-Jareño, H. Perrot, Charge compensation process in polypyrrole studied by ac electrogravimetry, Electrochim. Acta 46 (2001) 4095.

[38] A.R. Hillman, I. Efimov, M. Skompska, Time-temperature superposition for viscoelastic properties of regioregular poly(3-hexylthiophene) films, J. Am. Chem. Soc. 127 (2005) 3817.

[39] V.E. Granstaff., S.J. Martin, Characterization of a thickness-shear mode quartz resonator with multiple nonpiezoelectric layers, J. Appl. Phys. 75 (1994) 1319.

[40] G. Sauerbrey, The use of a quartz crystal oscillator for weighing thin layers and microweighing applications, Z. Phys. 155 (1959) 206.

[41] P. Camurlu, Polypyrrole derivatives for electrochromic applications, RSC Adv. 4 (2014) 55832.

[42] M.D. Levi, C. Lopez, E. Vieil, M.A. Vorotyntsev, Influence of ionic size on the mechanism of electrochemical doping of polypyrrole films studied by cyclic voltammetry, Electrochim. Acta 42 (1997) 757.

[43] C.R. Arias, C. Debiemme-Chouvy, C. Gabrielli, C. Laberty-Robert, A. Pailleret, H. Perrot, O. Sel, New Insights into Pseudocapacitive Charge-Storage Mechanisms in Li-Birnessite Type MnO2Monitored by Fast Quartz Crystal Microbalance Methods, J. Phys. Chem. C 118 (2014) 26551.

[44] O. Sel, L. To Thi Kim, C. Debiemme-Chouvy, C. Gabrielli, C. Laberty-Robert, H. Perrot, Determination of the diffusion coefficient of protons in Nafion thin films by ac-electrogravimetry, Langmuir 29 (2013) 13655.

[45] M.D. Levi, S. Sigalov, D. Aurbach, L. Daikhin, In Situ Electrochemical Quartz Crystal Admittance Methodology for Tracking Compositional and Mechanical Changes in Porous Carbon Electrodes, J. Phys. Chem. C 117 (2013) 14876.

[46] P.A. Christensen, A. Hamnett, In situ spectroscopic investigations of the growth, electrochemical cycling and overoxidation of polypyrrole in aqueous solution, Electrochim. Acta 36 (1991) 1263. 
[47] F. Beck, P. Braun, M. Oberst, Organic Electrochemistry in the Solid State-Overoxidation of Polypyrrole, Ber. Bunsenges. Phys. Chem. 91 (1987) 967.

[48] G. Lu, C. Li, G. Shi, Polypyrrole micro- and nanowires synthesized by electrochemical polymerization of pyrrole in the aqueous solutions of pyrenesulfonic acid, Polymer 47 (2006) 1778.

[49] J.L. Brédas, G.B. Street, B. Thémans, J.M. André, Organic polymers based on aromatic rings (polyparaphenylene, polypyrrole, polythiophene): Evolution of the electronic properties as a function of the torsion angle between adjacent rings, J. Chem. Phys. 83 (1985) 1323.

[50] S.S. Jeon, C. Kim, J. Ko, S.S. Im, Spherical polypyrrole nanoparticles as a highly efficient counter electrode for dye-sensitized solar cells, J. Mater. Chem. 21 (2011) 8146. 
Table 1 . Fitting parameters, $K_{i}$ and $G_{i}$, obtained from $a c$-electrogravimetry.

\begin{tabular}{|c|c|c|c|c|c|c|c|}
\hline & & $\begin{array}{c}K_{C} \\
\left(\times 10^{-4}\right)\end{array}$ & $\begin{array}{c}G_{c} \\
\left(\times 10^{-8}\right)\end{array}$ & $\begin{array}{c}K_{a} \\
\left(\times 10^{-6}\right)\end{array}$ & $\begin{array}{c}G_{a} \\
\left(\times 10^{-9}\right)\end{array}$ & $\begin{array}{c}K_{s} \\
\left(\times 10^{-5}\right)\end{array}$ & $\begin{array}{c}G_{S} \\
\left(\times 10^{-8}\right)\end{array}$ \\
\hline \multirow{3}{*}{$-0.2 \mathrm{~V}$} & fresh film & 6.518 & 26.17 & 25.51 & -47.19 & 8.796 & 24.63 \\
\hline & 100 -cycle & 3.826 & 11.86 & 17.59 & -23.75 & 25.95 & 33.73 \\
\hline & 175-cycle & 3.607 & 7.934 & 11.61 & -11.61 & 31.67 & 23.75 \\
\hline \multirow{3}{*}{$-0.6 \mathrm{~V}$} & fresh film & 7.213 & 28.85 & 40.46 & -32.37 & 15.83 & 31.67 \\
\hline & 100 -cycle & 8.005 & 7.204 & 39.58 & -18.21 & 17.59 & 24.63 \\
\hline & 175-cycle & 5.278 & 1.847 & 9.676 & -4.645 & 2.815 & 3.659 \\
\hline
\end{tabular}

Note: $\mathrm{cm} \cdot \mathrm{s}^{-1}$ and $\mathrm{mol} \cdot \mathrm{s}^{-1} \cdot \mathrm{cm}^{-2} \cdot \mathrm{V}^{-1}$ are for the units of $K$ and $G$ parameters, respectively. Cation, anion and solvent in the Table refer to $\mathrm{Na}^{+}$or hydrated $\mathrm{Na}^{+}, \mathrm{Cl}^{-}$and free $\mathrm{H}_{2} \mathrm{O}$. For 175 -cycled film at $-0.6 \mathrm{~V}$, the fitting parameters for $\mathrm{DS}^{-}$are $K=2.815 \times 10^{-3} \mathrm{~cm} \cdot \mathrm{s}^{-1}$ and $G=-2.815 \times 10^{-8} \mathrm{~mol} \cdot \mathrm{s}^{-1} \cdot \mathrm{cm}^{-2} \cdot \mathrm{V}^{-1}$.
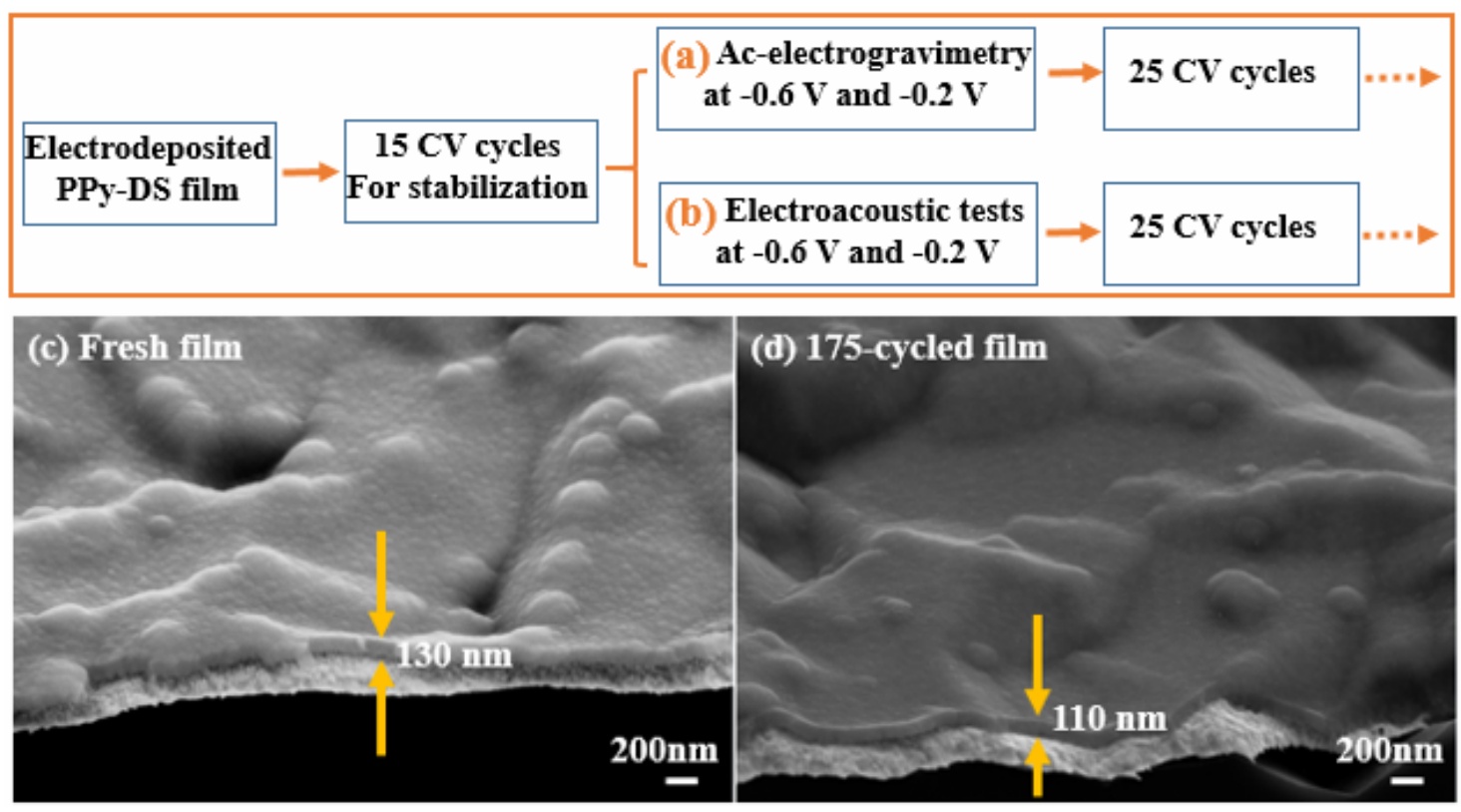

Figure 1. Schematic illustration of the measurement procedures for (a) $a c$-electrogravimetry and (b) electroacoustic tests during film electrochemical cycling as 
well as (c) and (d) are the morphological observations of electrodeposited fresh and 175-cycled PPy-DS film by FEG-SEM, respectively.
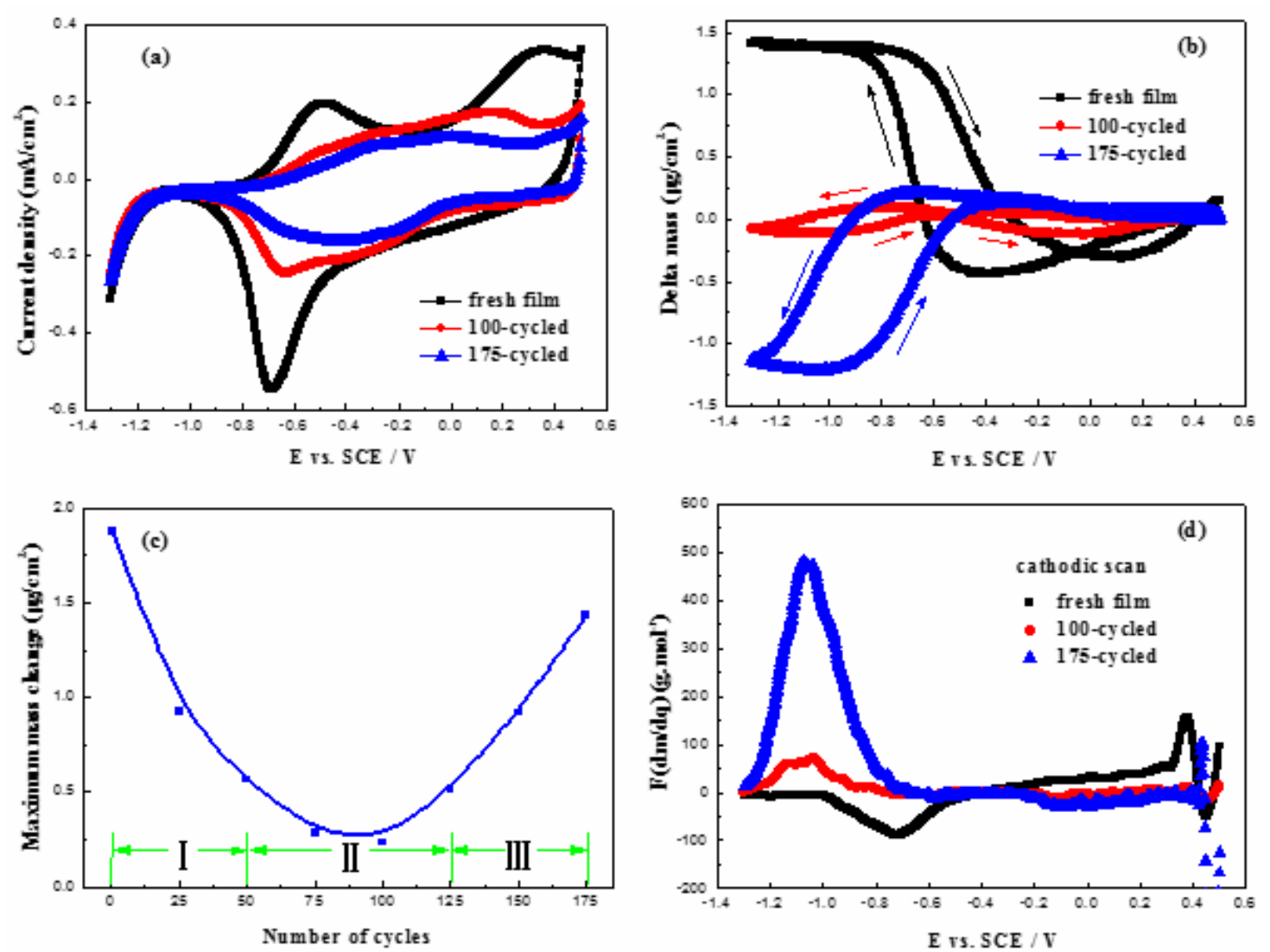

Figure 2. Cyclic voltammetry (a), mass change $(\Delta m)(\mathrm{b})$, the maximum mass change (c) and $F(d m / d q)$ function calculated from the reduction branch (d) of PPy-DS film in 0.25 $\mathrm{M} \mathrm{NaCl}$ aqueous solution between $-1.3 \mathrm{~V}$ and $0.5 \mathrm{~V} v s$. SCE at a scan rate of $50 \mathrm{mV} \cdot \mathrm{s}^{-1}$.
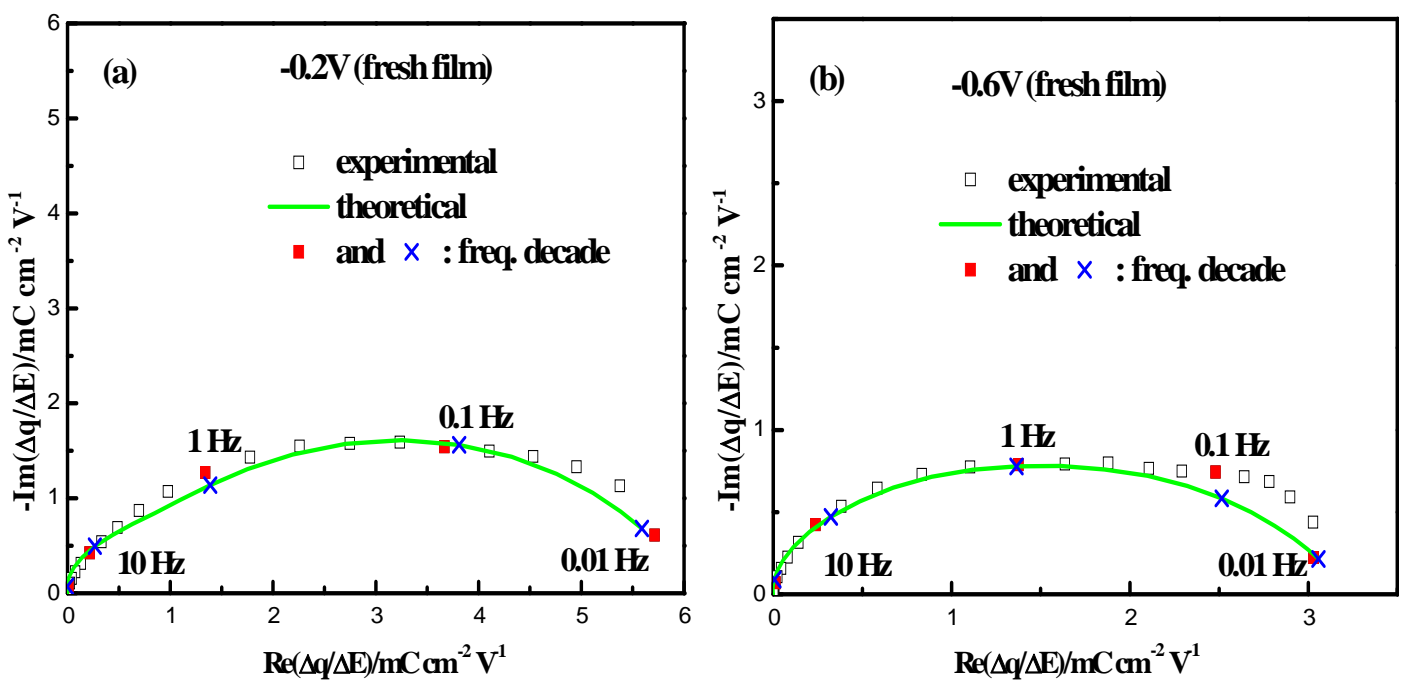

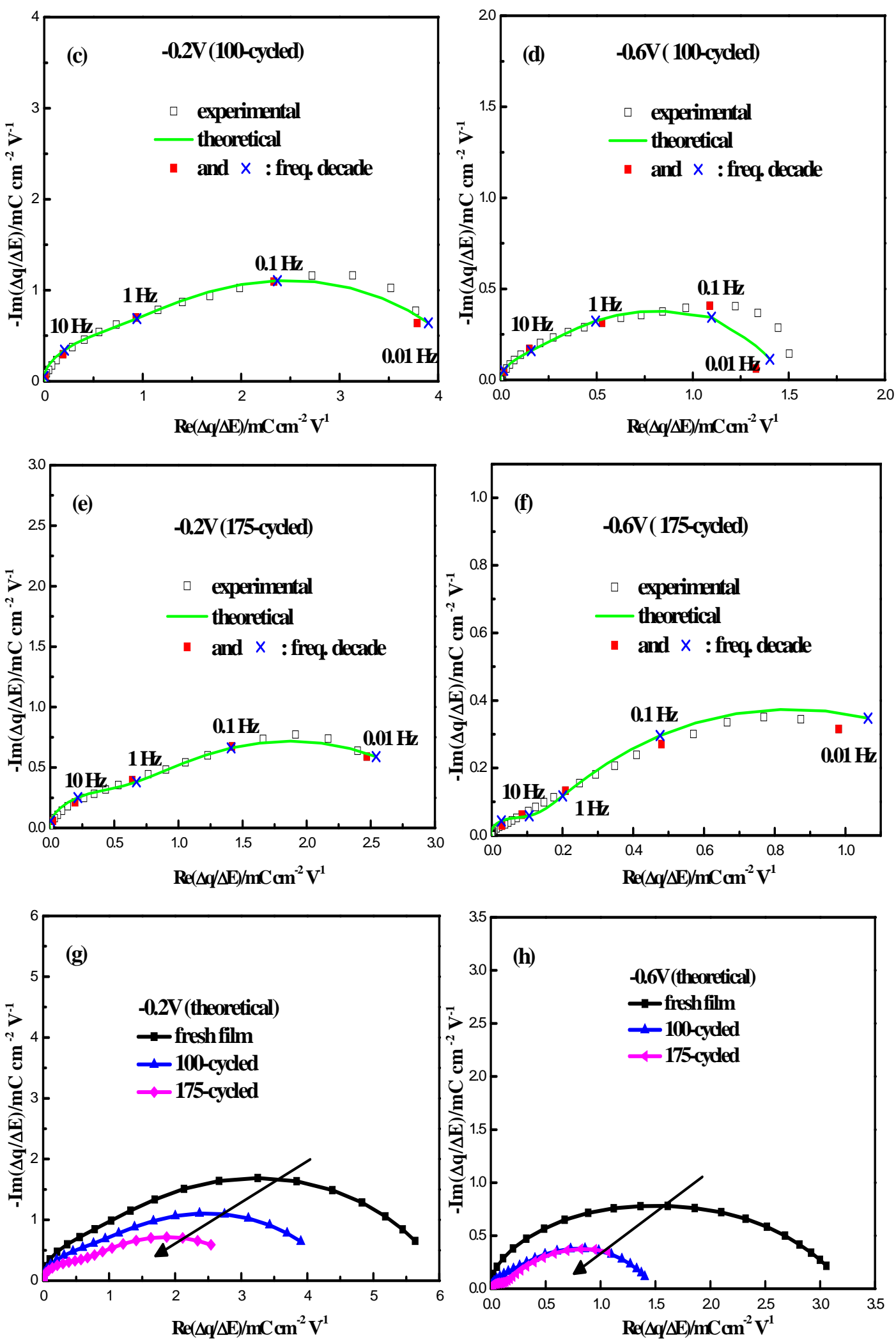

Figure 3. Experimental and theoretical $\Delta q / \Delta E(\omega)$ transfer functions for PPy film at different cycled state: (a), (c) and (e) were measured for fresh film, 100- and 175-cycled 
film at $-0.2 \mathrm{~V}$, while (b), (d) and (f) at $-0.6 \mathrm{~V}$, respectively. Panels (g) and (h) are theoretical TFs of $\Delta q / \Delta E(\omega)$ as film cycled at $-0.2 \mathrm{~V}$ and $-0.6 \mathrm{~V}$.
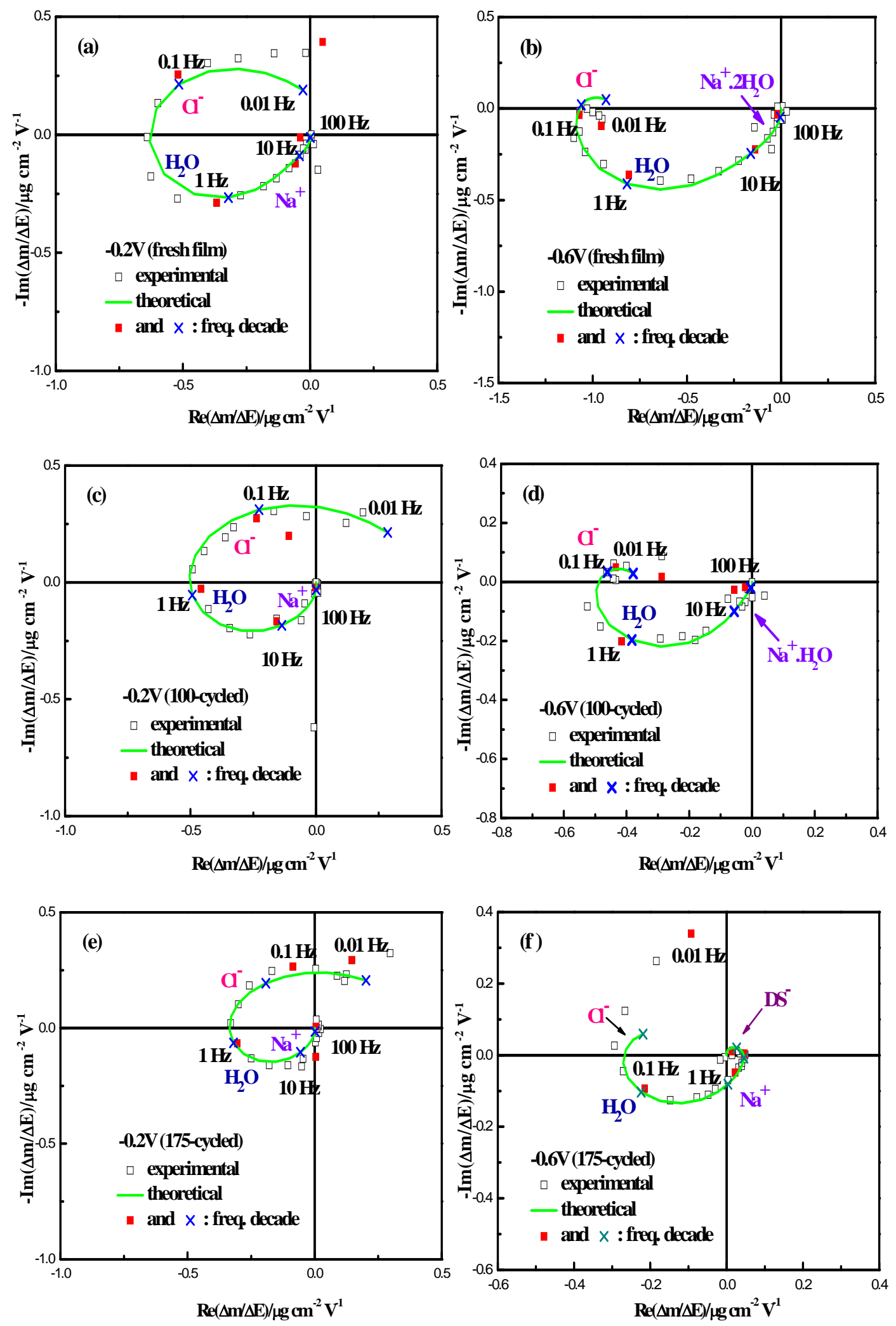

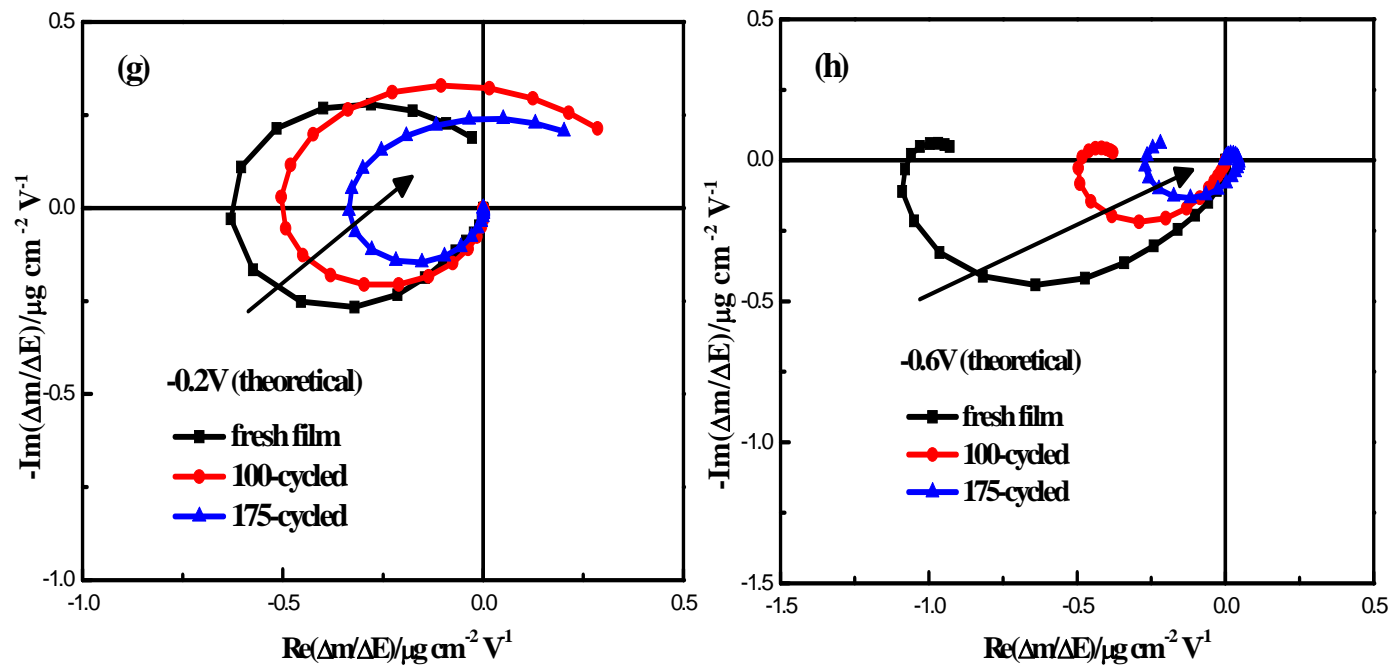

Figure 4. Evolution of transfer function of $\Delta m / \Delta E(\omega)$ with film cycling: (a), (c) and (e) were measured for fresh film, 100- and 175-cycled film at -0.2V, (b), (d) and (f) at $-0.6 \mathrm{~V},(\mathrm{~g})$ and $(\mathrm{h})$ theoretical TFs of $\Delta m / \Delta E(\omega)$ as film is cycled at $-0.2 \mathrm{~V}$ and $-0.6 \mathrm{~V}$, respectively.
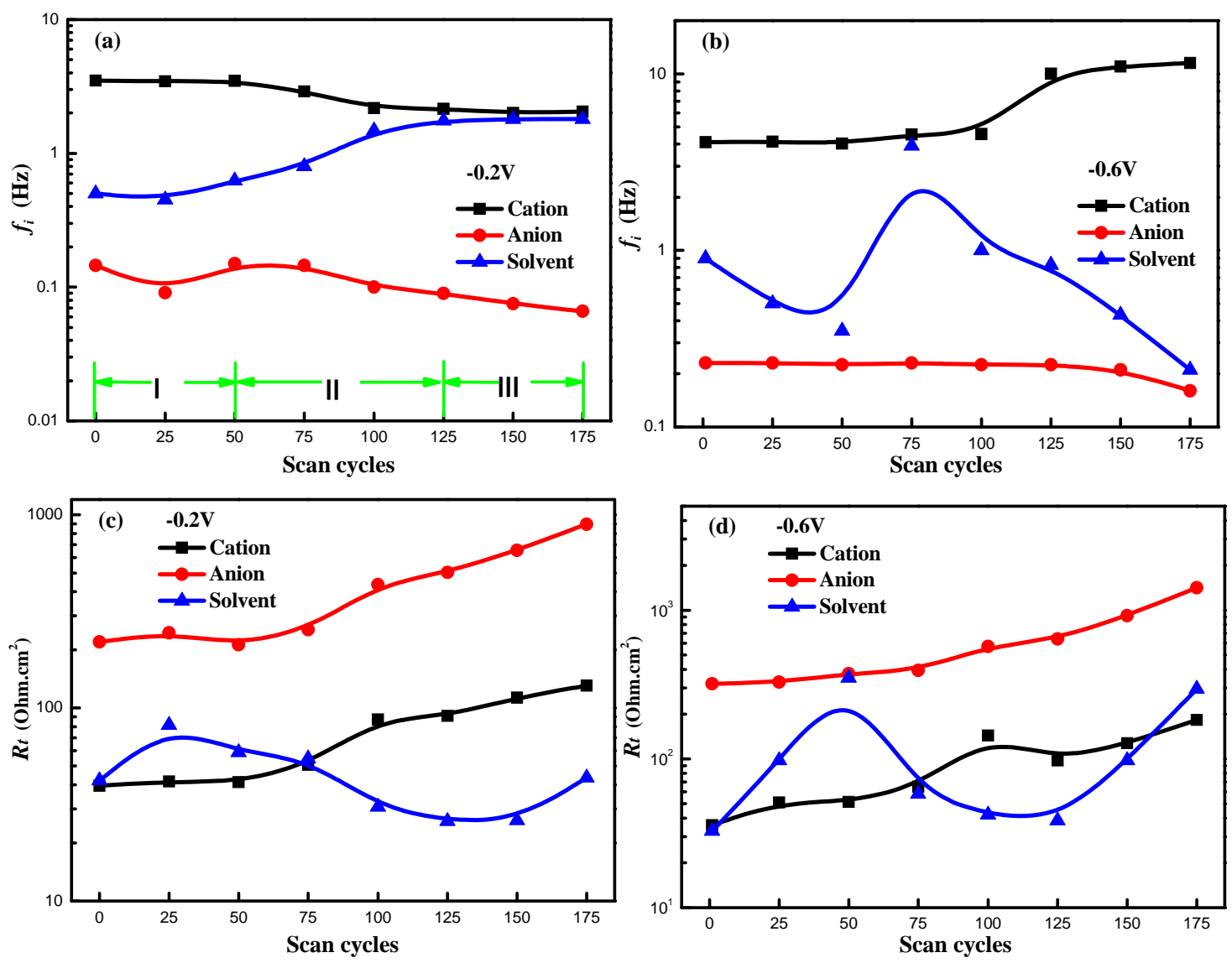

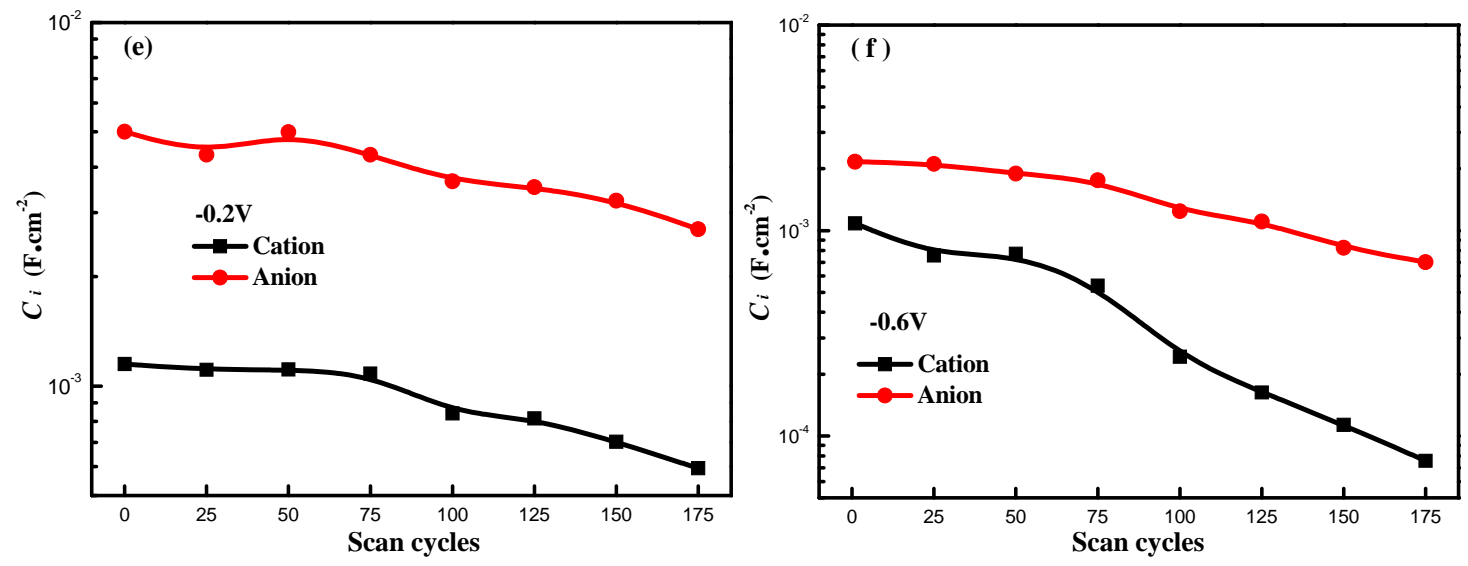

Figure 5. (a), (b) Evolution of characteristic frequency $\left(f_{i}\right)$. (c), (d) transfer resistance $\left(R t_{i}\right)$ and (e), (f) instantaneous capacitance $\left(C_{i}\right)$ for each species at two different potentials as the film is electrochemically cycled. Herein, anion only refers to $\mathrm{Cl}^{-}$.
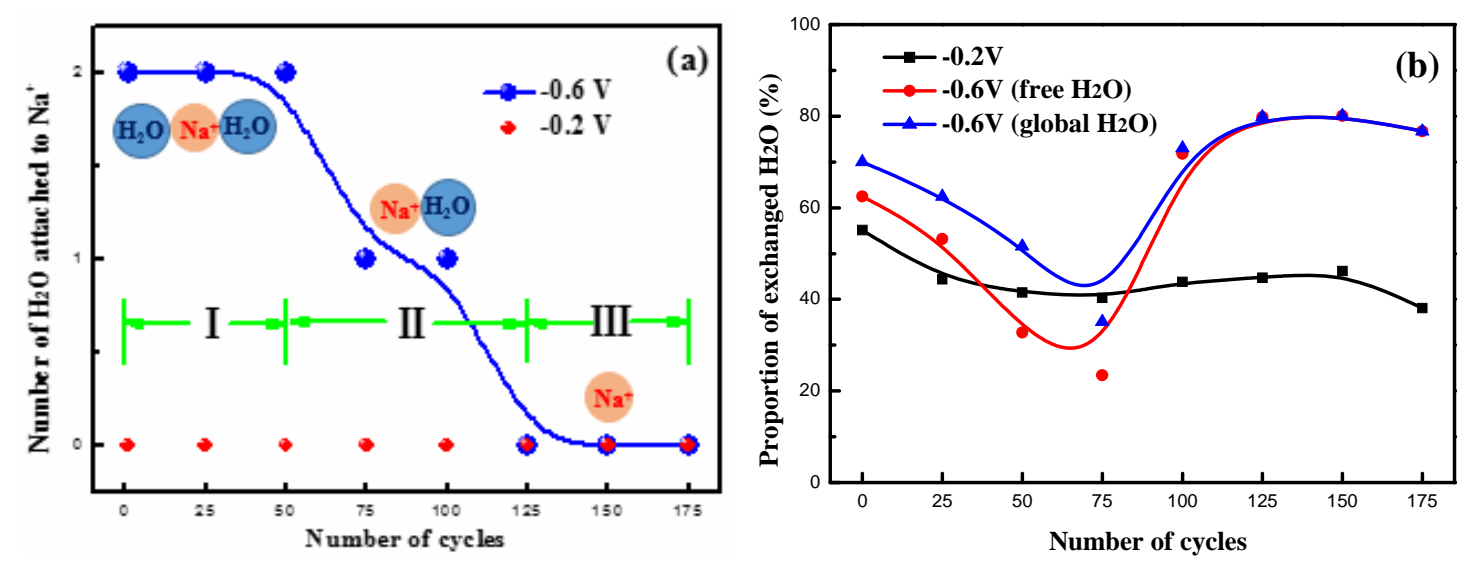

Figure 6. (a) Dehydration process for hydrated cations $\left(\mathrm{Na} \cdot 2 \mathrm{H}_{2} \mathrm{O}\right)$ transferred at the film/solution interface at $-0.6 \mathrm{~V}$ as the film is electrochemically cycled, and (b) proportion of exchanged $\mathrm{H}_{2} \mathrm{O}$ (calculated using eq. 12 and 13) participating in charge compensation at both potentials. Global $\mathrm{H}_{2} \mathrm{O}$ represents the sum of free $\mathrm{H}_{2} \mathrm{O}$ and the $\mathrm{H}_{2} \mathrm{O}$ molecules within the hydration shell of cations. 

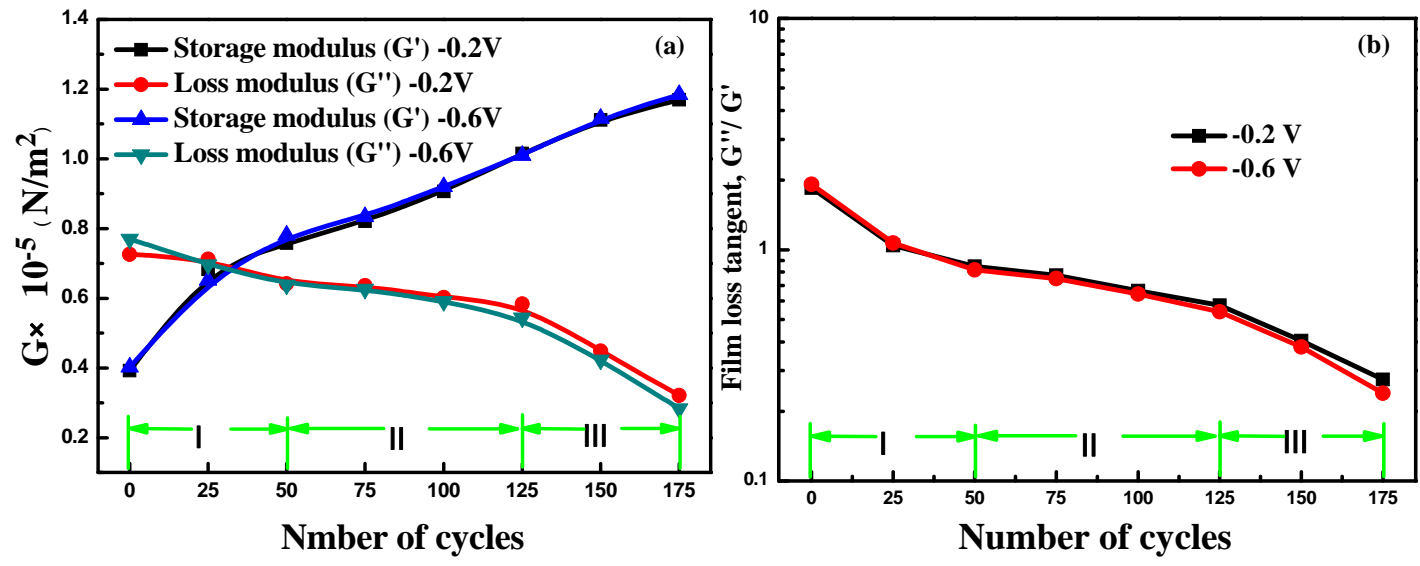

Figure 7. (a) Evolution of real and imaginary components of complex shear modulus and (b) film loss tangent during cycling at $-0.2 \mathrm{~V}$ and $-0.6 \mathrm{~V}$, respectively.

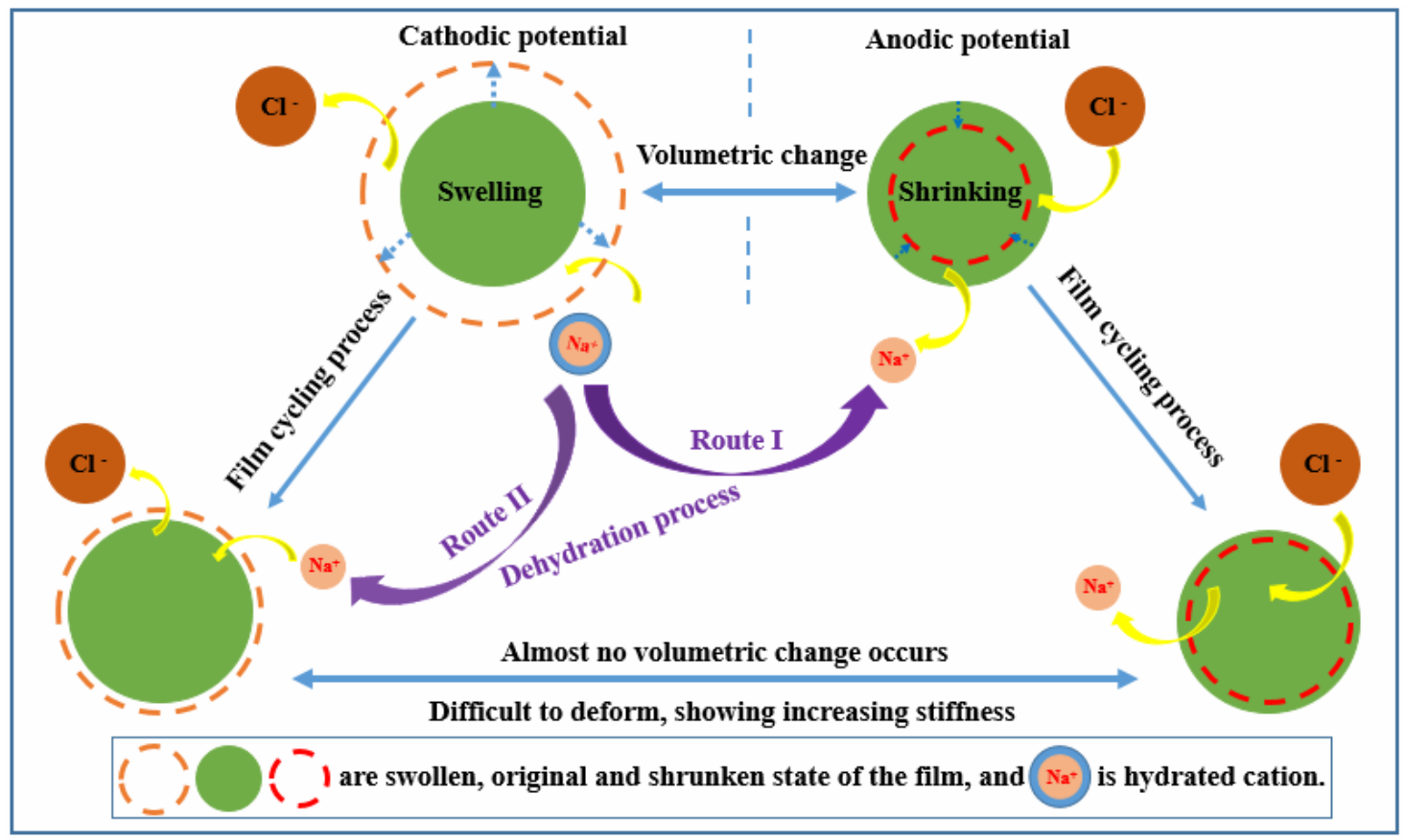

Figure 8. Schematic of volumetric evolution of PPy electrode during film cycling, without considering the exchange of free $\mathrm{H}_{2} \mathrm{O}$ molecules. 